\title{
Cooperativismo como alternativa para o desenvolvimento social no município de Igrejinha/rs - um estudo de caso no Sicoob Ecocredi
}

\section{Cooperativism as an alternative for social development in the municipality of Igrejinha / rs - a case study in Sicoob Ecocredi}

\section{Cooperativismo como alternativa para el desarrollo social en el municipio de Igrejinha / rs - un estudio de caso en el Sicoob Ecocredi}

DOI: http://dx.doi.org/10.25087/resur6a2

\author{
Alan Jones Trein ${ }^{1}$ \\ Prof. Dr. Marcos Paulo Dhein Griebeler ${ }^{2}$
}

Recibido, $1^{\circ}$ de diciembre de 2018

Aprobado, 15 de diciembre de 2018

\section{Resumen}

El cooperativismo está cada vez más presente en la vida cotidiana y las cooperativas desempeñan un importante papel social en las comunidades donde están insertadas, pues sus principios y valores están fundamentados en la solidaridad, libertad, reducción de desigualdades y promoción del bien común. En este contexto, este artículo tiene por objetivo analizar el Fondo Social y Comunitario (FSC), distribuido por SicoobEcocredi, y sus contribuciones al desarrollo social en el municipio de Igrejinha / RS. Para ello, se utilizó una investigación amparada en una revisión bibliográfica, utilizando como referencias autores renombrados que tratan de ese asunto, como Meinen y Port (2014), Schneider (2012), Pagnussatt (2004), Sen (1999), Ashley (2003), entre otros. En cuanto a los procedimientos metodológicos, esta investigación se caracteriza por un estudio de caso, bibliográfico y se utiliza del método cualitativo. Los datos fueron recolectados a través de un cuestionario con los gestores de la cooperativa y también con los responsables por las entidades beneficiadas por el FSC, además de una investigación documental. Los resultados demuestran que los participantes en la encuesta concuerdan que el FSC es muy importante para el municipio

\footnotetext{
${ }^{1}$ Acadêmico do Curso de Administração das Faculdades Integradas de Taquara -Faccat. Email:alantrein@sou.faccat.br

${ }^{2}$ Professor Orientador. Docente nas Faculdades Integradas de Taquara-Faccat. E-mail: marcosdhein@ faccat.br
} 
porque ayuda a las entidades en el desarrollo de su trabajo junto a la comunidad, mejorando la calidad de la atención prestada, que pasa a ser más rápido y eficiente. Se concluye que el FSC distribuido por SicoobEcocredi contribuye a la mejora del desarrollo social en el municipio de Igrejinha / RS.

Palabras clave: Cooperativismo. Desarrollo Social. Fondo Social y Comunitario. Educación social.

\section{Resumo}

O cooperativismo está cada vez mais presente no cotidiano e as cooperativas desempenham um importante papel social nas comunidades onde estão inseridas, pois seus princípios e valores são fundamentados na solidariedade, liberdade, redução de desigualdades e promoção do bem comum.Diante desse contexto, este artigo tem por objetivo analisar o Fundo Social e Comunitário (FSC), distribuído pelo SicoobEcocredi,e suas contribuições para o desenvolvimento social no município de Igrejinha/RS. Para tanto, utilizou-se uma pesquisa amparada em uma revisão bibliográfica, utilizando como referências autores renomados que tratam desse assunto, como Meinen e Port (2014), Schneider (2012), Pagnussatt (2004), Sen(1999), Ashley (2003) entre outros. Quanto aos procedimentos metodológicos, esta pesquisa é caracterizada por um estudo de caso, bibliográfico e utiliza-se do método qualitativo. Os dados foram coletados através de um questionário com os gestores da cooperativa e também com os responsáveis pelas entidades beneficiadas pelo FSC,alem de uma pesquisa documental.Os resultados demonstram que os participantes da pesquisa concordam que o FSC é muito importante para o municípioporque auxilia as entidades no desenvolvimento de seu trabalho junto à comunidade, melhorando a qualidade do atendimento prestado, que passa a ser mais rápido e eficiente. Conclui-se, que,o FSC distribuído pelo SicoobEcocredi contribui para a melhoria do desenvolvimento social no município de Igrejinha/RS.

Palavras-chave: Cooperativismo. Desenvolvimento Social. Fundo Social e Comunitário.Educação social. 


\begin{abstract}
Cooperativism is increasingly present in daily life, and it plays an important social role in the communities where they are inserted, because its principles and values are based on solidarity, freedom, reduction of inequalities and the promotion of common sense. Based on this, the purpose of this article is to analyze the Fundo Social Comunitário (FSC), by SicoobEcocredi, and his contributions to social development in the municipality of Igrejinha / RS. To write this article a research based on a (Schneider, 2012), Pagnussatt (2004), Sen (1999), Ashley (2003), and others was used. As for the methodological procedures, this research is characterized by a case study, bibliographical, using the qualitative method. The data were collected through a questionnaire made with the managers of the cooperative and also with those responsibles for the entities benefited by the FSC. The results show that the participants agree that FSC is very important for the municipality because it assists the entities in the development of their work in the community, improving the quality of care provided, which is faster and more efficient. It is concluded that the FSC distributed by SicoobEcocredi contributes to the improvement of social development in the municipality of Igrejinha / RS.
\end{abstract}

Keywords: Cooperativism. Social Development. Fundo Social Comunitário. Social Education.

\title{
1 INTRODUÇÃO
}

As cooperativas desempenham um importante papel social nas comunidades onde atuam, visto que, uma de suas maiores características é a solidariedade fundamentada em ações de ajuda mútua, desenvolvidas a partir de alternativas econômicas e sociais. Dentro deste contexto é perceptível o grande avanço das cooperativas de crédito dentro do Sistema Financeiro Nacional (SFN), onde seu principal objetivo é melhorar a qualidade de vida de seus associados e da comunidade onde está inserida, buscando sempre unir crescimento econômico com bem-estar social.

"Os princípios cooperativistas são as linhas orientadoras através das quais as cooperativas levam a prática os seus valores" (MEINEN e PORT, 2012, p.31). Tomando como base os princípios do cooperativismo, em especial o sétimo princípio, que de acordo com a Aliança Cooperativa Internacional (ACI) é definido como: Interesse pela Comunidade - 
as cooperativas trabalham para o desenvolvimento sustentado das suas comunidades através de políticas aprovadas pelos membros.

Ao final de cada exercício social, as cooperativas, efetuam a apuração de seus resultados em balanço e, por se tratarem de sociedades sem fins lucrativos, distribuem aos seus associados, a título de sobras líquidas, o resultado positivo apurado. Seguindo os princípios do Cooperativismo, o SicoobEcocredi, criou em 2011 o Fundo Social e Comunitário (FSC), que visa estimular o desenvolvimento dos municípios e regiões em que atua. O Fundo é formado por uma percentagem das sobras líquidas, podendo receber doações de qualquer espécie, inclusive de associados e pode ser utilizado em projetos sociais, técnicos e educacionais. Sempre observando a preservação dos princípios da transparência, moralidade e isonomia; e o benefício direto ou indireto aos associados.

Com basenessas ponderações, formula-se o problema da pesquisa com a seguinte questão: Quais as contribuições do Fundo Social e Comunitário distribuído pelo SicoobEcocredi para o desenvolvimento social do município de Igrejinha?

Deste modo, o presente estudo tem como objetivo analisar o Fundo Social e Comunitário e suas contribuições para o desenvolvimento social no município de Igrejinha/RS.

Como objetivos específicos da pesquisa, foram estabelecidos os seguintes: a) Descrever a relevância do fundo social e comunitário do SicoobEcocredi; b) Identificar as contribuições do fundo social e comunitário para o desenvolvimento social no município de Igrejinha/RS; e c) Verificaros projetos amparados pelo fundo social e comunitário do SicoobEcocredi que alcançam um maior número de pessoas no município de Igrejinha/RS.

Esta pesquisa foi realizada no SicoobEcocredi, primeira cooperativa afiliada ao Sistema de Cooperativas de Crédito do Brasil (SICOOB), no Rio Grande do Sul no ano de 2010. Conforme dados coletados no site da cooperativa de crédito, em que este estudo será desenvolvido, atualmente a mesma é o maior sistema financeiro cooperativo do país, com mais de 3,5 milhões de associados e presente em 27 unidades da federação. O Sicoob possui mais de 33 mil colaboradores e dirigentes, sendo composta por cooperativas financeiras e empresas de apoio, que em conjunto oferecem aos associados serviços de conta corrente, crédito, investimento, cartões, previdência, consórcio, seguros, cobrança bancária,dentre outros. A unidade de estudo em questão é a agência localizada no município de Igrejinha/RS.

O tema é de importância econômica e social visto que o SicoobEcocredi, a partir do sétimo princípio do cooperativismo, o qual demonstra o interesse pela comunidade, vem 
seguindo uma tendência cada vez mais explorada. Com tal característica, assim como instituições pioneiras nesse conceito, as iniciativas sociais têm contribuído às comunidades em aspecto mundial, e, embora muitas delas utilizem estas iniciativas como parte integrante de um objetivo mercadológico de boa imagem, é evidente que estas práticas devem obter resultados a partir das convicções da organização.

O presente artigo está estruturado de forma que venha a atender às necessidades e entendimento de todos, seguindo os princípios da contextualização com qualidade e excelente entendimento do tema. Inicialmente, esta introdução ao assunto; $\mathrm{Na}$ seção seguinte, o referencial teórico abrangendo o conceito de cooperativismo e cooperativismo de crédito, princípios do cooperativismo, desenvolvimento humano e social e os conceitos principais de responsabilidade social.Posteriormente, descrevem-se os procedimentos metodológicos utilizados para alcançar os objetivos. Por fim, analisam-se os resultados da pesquisa e apresentam-se as considerações finais.

\section{Importância do Cooperativismo no Mundo}

Muitas são as formas de cooperação experimentadas pelo homem desde os primórdios até os dias atuais. Segundo Pinheiro (2008), a primeira cooperativa do mundo, na forma como hoje são conhecidas as sociedades cooperativas, foi a Sociedade dos Probos Pioneiros fundada em 1844 na Inglaterra por 28 tecelões. Apesar de existirem diversas outras experiências cooperativas anteriores, a constituição da cooperativa de consumo de Rochdale, é considerada o principal ponto de partida do cooperativismo moderno (SCHNEIDER, 2012).

“O cooperativismo origina-se da palavra cooperação. É uma doutrina cultural e socioeconômica, fundamentada na liberdade humana e nos princípios cooperativos" (GAWLAK, 2010, p.21). O conceito mais utilizado para o cooperativismo é o definido em 1995, no congresso daAliança Cooperativa Internacional - ACI, que diz: “Cooperativa é uma associação autônoma de pessoas unidas voluntariamente para atender às suas necessidades e aspirações econômicas, sociais e culturais comuns, através de uma empresa de propriedade conjunta e controlada democraticamente" (CONGRESSO CENTENÁRIO DA ACI, 1995).

Desta forma, a cooperativa é umaassociação de pessoas que se unem de forma voluntaria, possuindo interesses comuns com valores baseadosna responsabilidade, honestidade, solidariedade, equidade, liberdade e democracia.O cooperativismo de forma 
geral tem como objetivo principal o desenvolvimento social e a redução das desigualdades sociais dentro da comunidade onde está inserido.

Segundo Meinen e Port (2012) os valores do cooperativismo são imperativos morais e perduram ao longo do tempo, possuindo um alcance muito maior que o mundo cooperativista. Por isso, esses valores antecedem e servem de norte para os princípios, interligando grandes ideias a ações. AOrganização das Cooperativas Brasileiras - OCB (2017) menciona que "Os princípios cooperativos são as linhas orientadoras através das quais as cooperativas levam os seus valores à prática”, ou seja, os valores se materializam nos sete princípios cooperativistas.

Economias mais desenvolvidas, já utilizam, há bastante tempo, o cooperativismo como instrumento impulsionador de setores econômicos estratégicos. Alguns exemplos são encontrados especialmente em países como Alemanha, Bélgica, Espanha, Holanda, França e Portugal. Algumas experiências também merecem destaque, como a americana, a canadense e a japonesa (ALVES e SOARES, 2006)

Deste modo, Soares e Melo Sobrinho (2008) explicam que o cooperativismo é de singular importância para a sociedade, já que promove a aplicação de recursos privados e assume os riscos equivalentes em favor da comunidade onde se desenvolve. Como representa iniciativas dos próprios cidadãos, colabora de forma eficaz para o desenvolvimento local sustentável, principalmente para a formação de poupança e de financiamento de iniciativas empresarias, trazendo benefícios como a geração de empregos e a distribuição de renda.

\section{Resgate Histórico do Cooperativismo de Crédito e sua Evolução no Brasil}

A história do cooperativismo de crédito no mundo inicia-se na Europa, mais precisamente na cidade alemã de Delitzch, tendo Herman Schulze como seu precursor, criando em 1856 sua primeira cooperativa de crédito urbana a "associação de dinheiro antecipado"3(PINHEIRO, 2008). As cooperativas fundadas por Herman Schulze são conhecidas na Alemanha como bancos populares. Alguns anos mais tarde, mais precisamente em 1864, Friedrich Wilhelm Raiffeisen funda a primeira cooperativa de crédito rural na cidade de Heddesdorf na Alemanha (PAGNUSSATT, 2004). Segundo Meinen e Port (2014) o nome Raiffeisen ainda é usado na Áustria, pelo maior grupo bancário, o Raiffeisenbank, com filiais na Europa Central e Oriental, também por cooperativas de crédito rural na Alemanha e

\footnotetext{
3 "associação de dinheiro antecipado" foi a primeira cooperativa de crédito urbana criada em 1856 na cidade alemã de Delitzchl.
}

Rev. educ. super. sur glob - RESUR No. 6 Jul. Dic. 2018 e024

ISSN 2393-6789 
pelas CajasRuralesRaiffeisen na Itália. Já em 1865, surgem na cidade de Milão, na Itália, a primeira cooperativa do tipo Luzzati cujo modelo herdou o nome de seu fundador, o italiano Luigi Luzzatti, bastante comuns no Brasil entre os anos de 1940 e 1960 (PINHEIRO, 2008).

No Brasil, o cooperativismo de crédito teve início em 1902, com a criação da primeira cooperativa de crédito da América Latina, a Caixa de Economia e Empréstimos Amstad, localizada no município de Nova Petrópolis e idealizada pelo padre suíço Theodor Amstad, seguindo o modelo alemão denominado Raiffeisen (MEINEN e PORT, 2012). Essa cooperativa continua em atividade até os dias de hoje, sob a denominação de Cooperativa de Crédito de Livre Admissão de Associados Pioneira da Serra Gaúcha - SICREDI Pioneira RS.

Porém, a trajetória do cooperativismo brasileiro sofreu um forte revés por volta de 1965, quando, em razão da reformulação da legislação bancária, o Estado passou a ser responsável pelo financiamento subsidiado do desenvolvimento agropecuário e industrial, fazendo com que as cooperativas de crédito deixassem de ser instrumento para tais financiamentos, sendo então submetidas a restrições operacionais (MEINEN e PORT, 2012). A interferência do Banco Central - órgão responsável pela normatização e fiscalização do Sistema Financeiro Nacional (SFN) ocorreu devido ao forte poder político dos bancos comerciais que solicitavam ao governo a adoção de medidas que limitassem a atuação das cooperativas no setor financeiro (ETGETO et al. 2005).

No início dos anos 1980, o cenário começou a mudar devido à redução do volume de recursos oficiais destinados ao financiamento da atividade rural, deste modo as cooperativas de crédito passaram a se reorganizar no Brasil. Também em 1980, mais precisamente no dia27 de outubro, foi constituída a Cooperativa Central de Crédito do Rio Grande do Sul, com sede em Porto Alegre (RS), sendo considerada a mais antiga das atuais cooperativas centrais de crédito, autorizada a funcionar em 20 de fevereiro de 1981(PINHEIRO, 2008).

Segundo Pagnussatt (2004), o período de maior avanço para as cooperativas de crédito ocorreu por volta dos anos 1990. Foi a partir de ações lideradas pelas centrais ao Conselho Monetário Nacional (CMN), em 1992, que as cooperativas ganharam a permissão para captação de depósitos a prazo e, tempos depois, conquistaram a autorização para a abertura de postos de atendimento, sendo antes permitido atender somente na sede da cooperativa.

Em 1995, com a edição da Resolução no 2.193/95, pelo Conselho Monetário Nacional, permitiu-se a constituição dos bancos cooperativos, através dos quais as cooperativas passaram a ter acesso direto a todos os serviços financeiros, dando condições ao 
cooperativismo de crédito de atuar de forma independente e em condições competitivas com o sistema bancário convencional (PAGNUSSATT, 2004).

A partir de então ocorreram vários avanços no âmbito do cooperativismo de crédito em intervalos menores de tempo, que vem fortalecendo o setor. No ano de 2013, às cooperativas de crédito conquistaram uma antiga reivindicação, a regulamentação do Fundo Garantidor do Cooperativismo de Crédito (FGCoop) pelo Banco Central, colocando as cooperativas no mesmo patamar dos bancos, ampliando desta forma, a credibilidade das cooperativas no mercado e assegurando aos seus clientes os mesmos direitos já garantidos aos clientes de bancos convencionais (SCHARDONG, 2013).

Conforme Meinen e Port (2014), de modo geral, o cooperativismo financeiro avançou bastante através de inúmeras ações que contribuíram para este progresso, como a conquista em 2003 da livre admissão, a criação do FGCoop entre outras ações. Podendo-se afirma deste modo, que o setor teve uma década de muitas conquistas, que em conjunto com outros incentivos institucionais e regulamentares contribuíram para uma participação mais robusta e sustentável no âmbito do Sistema Financeiro Nacional (SFN).

\section{Interesse pela Comunidade: O Sétimo Princípio do Cooperativismo}

Os sete princípios do cooperativismo foram desenvolvidos através de ideais baseados na cooperação. Estes princípios foram aprovados e colocados em prática na fundação da primeira cooperativa formal do mundo, Rochdale, na Inglaterra, em 1844 (GAWLAK, 2010). Entretanto, para se adequar a evolução, modernização e expansão do cooperativismo e também da economia mundial, os princípios cooperativistas foram reestruturados. Meinen e Port (2012) destacam que estes princípios foram revisados nos anos de 1937, 1966 e 1995, durante congressos da ACI, e a lista originária desta última revisão permanece até hoje.

Para Schneider (2012) os valores e o espírito cooperativista estão materializados nos princípios do cooperativismo e estão formulados conforme definidos em 1995, sendo estes:

A adesão livre e voluntária é o primeiro dos princípios e significa que as cooperativas são organizações voluntárias e estão abertas ao ingresso de todas as pessoas dispostas a utilizarem seus serviços, sem discriminação de gênero, racial, social, religiosa ou política desde que estejam dispostas a assumirem suas responsabilidades enquanto sócios.

As cooperativas são organizações democráticas e controladas pelos seus membros, que participam de forma ativa nas decisões e também na formulação das políticas internas, desta 
forma, as pessoas eleitas como representantes dos demais sócios são responsáveis perante estes. A este se denomina, princípio da gestão e controle democrático por partes dos sócios.

O terceiro princípio diz respeito à participação econômica dos sócios que contribuem equitativamente para o capital da cooperativa e por este motivo controlam-no de forma democrática. Portanto, parte deste capital é propriedade comum da cooperativa.

O princípio da autonomia e independência refere-se ao fato de as cooperativas serem organizações autônomas e de ajuda mútua, administradas pelos sócios. Caso seja necessário algum tipo de acordo com outras organizações, incluindo as governamentais, deve-se assegurar o controle democrático dos seus membros e a sua autonomia.

A educação, treinamento e informação cooperativa é o quinto princípio cooperativista, resume a importância das cooperativas promoverem a educação e formação de seus colaboradores e cooperados, de forma que estes possam contribuir para o desenvolvimento de suas cooperativas, principalmente, informando o público em geral, como jovens e formadores de opinião, sobre a natureza e os benefícios da cooperação.

O princípio da cooperação intercooperativa explica que as cooperativas devem servir aos seus sócios de forma eficaz, fortalecendo o movimento cooperativo e trabalhando em conjunto nas estruturas locais, regionais, nacionais e internacionais.

O sétimo princípio retrata sobre o interesse pela comunidade e significa que as cooperativas devem trabalhar para o desenvolvimento sustentado das comunidades onde atuam através de políticas que são aprovadas por seus cooperados.De acordo comMeinen e Port (2014), esse interesse pela comunidade exige das cooperativas o apoio a projetos e soluções sustentáveis no âmbito social, ambiental e também econômico (para garantir a continuidade do próprio empreendimento cooperativo). Em resumo, as cooperativas devem trabalhar de forma contínua, visando à melhoria da qualidade de vida de todas as pessoas dentro da sua comunidade.

Klein (2014) destaca que o interesse pela comunidade como o sétimo dos princípios cooperativistas demonstra que já em meados do século XIX, as cooperativas praticavam os conceitos que hoje em dia são difundidos sob a denominação de responsabilidade social empresarial. Ou seja, enquanto as empresas passaram a se preocupar com o fator responsabilidade social apenas em anos mais recentes - após esse fator tornar-se um diferencial competitivo no mercado - nas cooperativas, o interesse pela comunidade sempre foi uma preocupação e esteve presente desde os primórdios de sua consolidação. Savoldi et al. (2011), também salienta que a responsabilidade social nas cooperativas é intrínseca aos 
valores que as moldaram desde o início e que as cooperativas devem conscientizar seus funcionários e cooperados que o suporte e envolvimento com a comunidade é imprescindível para que haja um desenvolvimento local de forma integrada e sustentável.

Neste mesmo sentidoMeinen e Port (2012) acrescentam que é necessário observar os princípios e a vocação socioeconômica das cooperativas porque essas têm total direito de atrair para si a qualificação de ser a melhor e mais verdadeira iniciativa socioeconômica comunitária. Ainda, segundo o autor, as cooperativas têm o dever de encaminhar as comunidades nas quais estão inseridas para um desenvolvimento equilibrado e de bem-estar, o que significa que elas devem respeitar as particularidades sociais e a vocação econômica do local, desenvolvendo soluções de negócios e apoiando ações em prol da comunidade.

\section{Desenvolvimento Humano e Social}

No começo do século XX, o desenvolvimento dos países era qualificado de acordo com o seu crescimento econômico, tendo como referência diversos indicadores econômicos. A partir da década de 1970 houve uma transformação importante nas abordagens e práticas do desenvolvimento, influenciados por alguns fatores decisivos como: (a) frustração dos países subdesenvolvidos perante os modelos de desenvolvimento propostos a eles; (b) aparecimento de visíveis sintomas de mal-estar social em países desenvolvidos; (c) crescimento de uma consciência ambiental frente aos problemas gerados pelo desenvolvimento; (d) crescimento econômico abalado por persistentes crises economicas; (e) países socialistas com crises e mal estares sociais, ambientais, econômicos e políticos (AMARO, 2003).

Segundo Rigueiro (2014), por se tratar de um fenômeno complexo e multidimensional, o desenvolvimento, não possui uma definição explícita e totalmente clara, sendo inúmeras as contribuições para o conceito de desenvolvimento. Assim ao longo do tempo, diversos adjetivos foram associados ao termo desenvolvimento, como, desenvolvimento local, sustentável, humano, participativo e social.

Considerava-se, como medida para o desenvolvimento, o aumento do Produto Interno Bruto (PIB) per capita, ou seja, acreditava-se que o aumento do crescimento econômico contribuiria ou aumentaria o desenvolvimento do país. Da deficiência deste conceito, surgiu o desenvolvimento sustentável, visto que o padrão de consumo das sociedades desenvolvidas é elevado, reforçando a ideia de que o desenvolvimento precisa satisfazer o bem-estar da 
população, ao mesmo tempo em que, não prejudica as gerações futuras, observando o meio social e ambiental (BECKER, 2001).

Para Buarque (1999), o desenvolvimento local é um processo endógeno, observado em unidades territoriais pequenas e alguns agrupamentos humanos que busca melhorar a qualidade de vida das pessoas e promover o dinamismo econômico. Deste modo, o mesmo autor define o desenvolvimento local como um processo de mudança social que busca o aumento das oportunidades da sociedade, de maneira que seja compatível, no tempo e no espaço, com o crescimento e a eficiência econômica, a conservação ambiental, a equidade social e a qualidade de vida, mantendo uma clara preocupação com o futuro das gerações.

Na visão de Sachs (2000), o termo desenvolvimento social passou a ser mundialmente utilizado após ser introduzido nos relatórios elaborados periodicamente pelas Nações Unidas sobre a situação social mundial. No começo era mais utilizado como um complemento de desenvolvimento econômico ou ainda para substituir a idéia de situação social. Os conceitos de social e econômico eram considerados distintos, por isso no ano de 1962, o Conselho Econômico e Social das Nações Unidas (ECOSOC) recomendou que esses dois conceitos fossem integrados como dois aspectos de desenvolvimento (SACHS, 2000).

Sachs (2000) ainda explica que o Instituto de Pesquisa das Nações Unidas para o Desenvolvimento Social (UNRISD) foi criado no ano de 1963, atendendoàs preocupações vigentes na época com o meio social. O UNRISD (2011) define que o desenvolvimento consiste em processos de mudanças para o bem-estar humano, de forma que estas mudanças devem ser sustentáveis e compatíveis com princípios de democracia e justiça social.

No ano de 1965, o Conselho Econômico e Social das Nações Unidas criou por meio de resolução o Programa das Nações Unidas para o Desenvolvimento (PNUD), estando presente em aproximadamente 170 países do mundo auxiliando-os na proteção dos direitos humanos e na igualdade de gênero e raça. Conforme dados coletados no site do Programa das Nações Unidas para o Desenvolvimento - PNUD (2017), o Desenvolvimento Humano é "um processo de ampliação das escolhas das pessoas para que elas tenham capacidades e oportunidades para serem aquilo que desejam ser", focando-se diretamente no bem-estar social das pessoas, nas suas capacidades e na vida que valorizam.

O desenvolvimento social também pode ser entendido como um "[...] processo de garantia de condições sociais mínimas, bem como de promoção da dimensão social, do bemestar, por parte dos responsáveis dos vários países e organizações internacionais" (AMARO, 2003, p. 59). Segundo o mesmo autor, este conceito surgiu no ano de 1995 na Conferência de 
Copenhaga, organizada pela Organização das nações Unidas (ONU), com o objetivo de debater e listar os principais problemas sociais do desenvolvimento.

Godoy (2004) ressalta que, empresas têm um papel básico atribuído à sociedade, onde os bens adquiridos são essenciais para estas, dessa maneira as cobranças sobre estas empresas, falando socialmente, devem ser ponderadas, já que, de certa forma estas, já tem uma parcela de contribuição. Contudo,Sen (1999), afirma que este desenvolvimento não deve ser generalizado na forma de acumulação de riquezas e crescimento de PIB, deve ser direcionado para a melhoria da qualidade de vida e da liberdade das pessoas, considerando que esta liberdade forneça embasamentos para que as pessoas escolham a vida que querem seguir.

Ainda conforme Sen (1999) a população possui um importante papel para o fortalecimento das responsabilidades sociais das empresas, já que, tem o poder de selecionar, no ato do consumo, aqueles produtos ou serviços que foram produzidos de forma responsável. Desta maneira, as pessoas são protagonistas, capazes de requerer mudanças, conforme seus valores e objetivos, sendo que a vida ocorre em cada local, cada lugar tem suas necessidades e diretrizes, tornando cada vez mais essencial a participação popular na política da sociedade.

\section{Principais Conceitos de Responsabilidade Social e a sua Importância para as}

\section{Comunidades}

É cada vez maior a preocupação dos gestores das organizações para com a responsabilidade social, visto que a uma busca constante das organizações em garantir o crescimento e a sobrevivência no mercado. Para Ashley (2003), a responsabilidade social pode ser definida como o compromisso que as organizações têm perante a sociedade, através de atos e atitudes positivas que contribuam para o desenvolvimento da sociedade ou comunidade em que está inserida. Deste modo, a responsabilidade social é um valor que vem se tornando aceito e empregado em todo o mundo principalmente em decorrência das mudanças no modo como a sociedade passou a perceber o papel social da empresa.

Commodaro e Sabatiello (2011) explicam que:

Pode-se definir responsabilidade social como a forma de gestão que se caracteriza pela relação ética e transparente da empresa com todos os públicos com os quais se relaciona e pelo estabelecimento de metas empresariais compatíveis com o desenvolvimento sustentável da sociedade, preservando recursos ambientais e culturais para as gerações futuras, respeitando a 
diversidade e promovendo a redução das desigualdades sociais (COMMODARO E SABATIELLO, 2011, p.11-12).

A responsabilidade social passou a ser um dos grandes fatores inclusive para análise de investimentos por parte de outras pessoas ou organizações. Atualmente, a preocupação com o futuro das próximas gerações, tornou-se uma prioridade e, portanto, é muito importante observar as empresas e entidades que se preocupam com a comunidade. Tanto na preservaçãodos recursos ambientais e culturais, como no auxílioda redução de desigualdades sociais.

A responsabilidade social pode ser definida em ações internas ou externas das empresas com seus colaboradores, atingindo a sua comunidade ou determinados grupos da sociedade. Antigamente, eram comuns atividades filantrópicas, que buscavam apenas situações individuais de carência e com entidades específicas, mas atualmente pode-se fazer com qualquer situaçãoque a empresa julgar relevante para o crescimento social e ambiental da sociedade (SOUZA, 2006).

Segundo Commodaro e Sabatiello (2011), há três campos de atuação da responsabilidade social: o ambiente de trabalho, o meio ambiente e a comunidade. Quanto ao ambiente de trabalho, atualmente refere-se mais a questões morais e éticas como, por exemplo, respeito à diversidade e um ambiente seguro para se trabalhar. $\mathrm{O}$ foco atual é o meio ambiente e a comunidade, pois vão além da empresa e representam um sentimento de responsabilidade, cumprido por espontaneidade e atitude, não somente nas obrigações da entidade ou empresa, mas com o social (COMMODARO E SABATIELLO, 2011).

O termo responsabilidade social remete para uma gestão da organização, somados a uma governança ética e sustentável e a um conjunto de responsabilidades voluntárias que a empresa assume para administrar seus impactos ambientais, econômicos e sociais produzidos na sociedade. Buscando assim, tornar compatíveis seus objetivos financeiros junto aos seus acionistas com os objetivos das partes interessadas da empresa, ou seja, todas aquelas que possuem algum vínculo a empresa, comprometendo-se com a geração de benefícios para a sociedade onde se encontra inserida (DIAS, 2012).

Conforme Melo Neto e Froes (2001), a responsabilidade social é um avanço a mais na execução da cidadania. Tudo começou através de ações filantrópicas, onde os grandes empresários queriam de alguma maneira beneficiar a sociedade com parte dos seus lucros, tal ato reflete-se como caridade as pessoas.Ainda, segundo Melo Neto e Froes (2001), a 
responsabilidade social não condiz diretamente com a filantropia, é muito mais uma consciência social e dever cívico. Não é uma ação isolada, mostra respeito perante a sociedade e estímulo à cidadania corporativa, contudo existe uma ação conjunta entre responsabilidade social e cidadania empresarial.

Porém, segundo Maximiano (2010), a corrente alternativa da responsabilidade social, propõe que a empresa tem obrigações essencialmente com seus acionistas. O principal representante desta doutrina foi o norte-americano Milton Friedman, economista da universidade de Chicago, ele defendia que em uma economia livre as empresas deveriam se preocupar, exclusivamente, em gerar lucros aos seus acionistas, não havendo fundamento algum para exigir das empresas qualquer tipo de atividade que se oponha aos fins para os quais foram criadas. Segundo Dias (2012), os defensores dessa abordagem são contra a intervenção da empresa no meio social, pois acreditam que é uma área que compete à ação política e à administração pública, além de outras entidades, que foram concebidas com funções sociais, como igrejas, sindicatos e organizações sociais.

Os argumentos a favor, conforme Ashley (2003) partem principalmente dos trabalhos mais recentes de Carroll, Donaldson e Dunfee, Frederic e Wood. Dias (2012) explica que os defensores das políticas de responsabilidade social defendem que a função social da empresa vai além da criação de valor para os acionistas e o cumprimento da legislação, defendendo a obrigação da empresa para com a sociedade. Em geral, as empresas podem ser beneficiadas, ao menos no longo prazo, por sua conduta socialmente responsável, visto que, através dela é possível explorar novas oportunidades de negócios que deverão surgir a partir da preocupação com os anseios sociais, culturais e ambientais, tornando a empresa mais competitiva e se diferenciando de seus concorrentes menos responsáveis (DIAS, 2012).

Para Srour (2003, p.316), a responsabilidade social é “[...] o compromisso das empresas com o bem-estar social", ou seja, quando estas empresas revertem seus lucros em melhorias sociais. Em conseqüência, as empresas abandonam velhas políticas, definem novas práticas, evoluem parcerias com as partes interessadas e isso mostra que estão preocupadas com o social. As organizações, assim como as pessoas, possuem responsabilidades sociais, na proporção de que sua postura afeta os demais e, sempre haverá, pessoas ou grupos dispostos a cobrar essa responsabilidade por diversos meios, como imprensa, legislação, ativismo político e atuação dos parlamentares (MAXIMIANO, 2010).

Ashley (2003) explica que a ética e a responsabilidade social são temas que estão em constante ascensão no Brasil, o cenário já evolui bastante desde a década de 1970, com 
importantes passos no final dos anos de 1990, através do lançamento de premiações importantes, do aumento da produção acadêmica e a fundação de diversas organizações associativistas promotoras deste conceito. Ainda, conforme a autora é importante ressaltar a preocupação das academias e das instituições de ensino superior com o tema da responsabilidade social empresarial, visto que, as mesmas vem incorporando-o em seus principais cursos, bem como em encontros específicos, como workshops, seminários, congressos e ainda, em um dos maiores eventos acadêmicos da área de Administração - $\mathrm{O}$ Encontro Anual da Associação dos Cursos de Pós-Graduação em Administração (Enanpad).

\section{METODOLOGIA}

Para alcançar os objetivos desta pesquisa, utilizou-se como procedimentos metodológicos um referencial teórico baseado nos principais pontos do estudo. A pesquisa caracteriza-se quanto aos seus objetivos como exploratória, com o objetivo central a identificação das contribuições do Fundo Social e Comunitário para o desenvolvimento social. Este projeto de pesquisa se define como um estudo de caso, e a pesquisa foi aplicada em uma cooperativa do ramo de crédito, em sua agência localizada no município de Igrejinha, no Rio Grande do Sul. Com relação aos procedimentos técnicos a pesquisa é caracterizada como bibliográfica. A pesquisa tem caráter documental, que de acordo com Martins (2008) podem ser compostos por documentoscomo materiais não editados, cartas, relatórios, propostas, estudos etc.

O universo da coleta de dados foi os gestores das entidades e/ou associações igrejinhenses que são beneficiadas pelo Fundo Social e Comunitário do SicoobEcocredi. Foram utilizadas amostras não probabilísticas de forma intencional, ou seja, o pesquisador se direciona, de forma intencional as pessoas que lhe interessam na pesquisa.A aplicação ocorreu em local e horário previamente combinado e agendado de acordo com a disponibilidade de cada entrevistado, no período compreendido entre os meses de junho e julho de 2017. Já a pesquisa documental, foi realizada no mês de maio de 2017 na sede administrativa do SicoobEcoredi localizada no município de Três Coroas/RS.

A amostra foi composta por 7 sujeitos de pesquisa, sendo 2 deles gestores. Os sujeitos integrantes da amostra assinaram o termo de Consentimento Livre e Esclarecido (TCLE), que trouxe informações e esclarecimentos, garantindo que os seus direitos fossem preservados com sigilo e privacidade. 
A coleta de dados foi primeiramente através de uma pesquisa documental, onde foram consultados documentos como estatutos, atas, e projetos que auxiliaram na identificação do processo de distribuição do Fundo Social e Comunitário. A segunda parte da coleta de dados foi por meio da aplicação de duas entrevistassemi-estruturadas. Uma, contendo 6 questões na modalidade aberta, designado a 5 sujeitos de pesquisa, representantes das entidades e/ou associações, e a outra contendo 5 perguntas abertas, destinado a 2 gestores participantes da amostra. As entrevistas foram aplicadas pelo pesquisador com os sujeitos mencionados, sendo seu conteúdo gravado em forma de áudio.

Nesta pesquisa foi utilizada a análise interpretativa.Após a coleta de dados é necessário que se faça a análise e interpretação destes. A intepretação tem como objetivo buscar um sentido mais amplo para as respostas, apartir de sua ligação a conhecimentos adquiridos anteriormente. $\mathrm{E}$ a análise dos dados tem como finalidade organizá-los de forma que permitam o fornecimento de respostas ao problema do trabalho (GIL, 2009).

\section{ANÁLISE DE RESULTADOS}

\subsection{Análise documental}

O SicoobEcocredi iniciou suas atividades a partir da inauguração da sua primeira agência cooperativa, filiada ao Sistema Sicoob no Rio Grande do Sul, no dia 12 de Abril de 2010 no município de Três Coroas/RS, fruto dos esforços de empresários da região associados ao Sindicato da Indústria de Calçados, Componentes para Calçados de Três Coroas/RS. Graças a estas pessoas foi possível alcançar o número de 250 sócios fundadores que apostaram no desenvolvimento mútuo da região.O nome, sugerido e aprovado na assembleia, vem de ecologia - uma referência às belezas naturais da região, com resquícios da mata atlântica.

Com base nos princípios do cooperativismo, no ano de 2011, o SicoobEcocredi, criou o Fundo Social e Comunitário (FSC), que visa estimular o desenvolvimento dos municípios e regiões em que atua. O fundo é formado por uma percentagem das sobras líquidas, podendo receber doações de qualquer espécie, inclusive de associados e pode ser utilizado em projetos sociais, técnicos e educacionais. Sempre observando a preservação dos princípios da transparência, moralidade e isonomia, alémdo benefício direto ou indireto aos associados. 
No ano de 2012 foram escolhidas onze entidades nos municípios de Igrejinha e Três Coroas, para as quais foram divididos o valor de $\mathrm{R} \$ 70.000,00$, sendo que as entidades beneficiadas no município de Igrejinha foram o Hospital Bom Pastor, Corpo de Bombeiros Voluntários e Associação de Pais e Amigos dos Excepcionais (APAE). No ano seguinte, de 2013, o montante dividido foi de $\mathrm{R} \$ 100.819,57$ entre nove entidades dos municípios de Igrejinha e Três Coroas, sendo que, no município de Igrejinha, as entidades auxiliadas foram às mesmas do ano de 2012.

Em 2014,os municípios de Igrejinha, Três Coroas e Novo Hamburgo tiveram nove entidades escolhidas, onde o montante dividido foi de $\mathrm{R} \$ 196.583,89$, sendo que foram auxiliadas a APAE, Esporte Clube Igrejinha, Corpo de Bombeiros Voluntários e oHospital Bom Pastor no município de Igrejinha. No ano de 2015 foram onze entidades escolhidas nos municípios de Igrejinha, Três Coroas, Novo Hamburgo e Gramado para as quais foram distribuídos o valor de $\mathrm{R} \$ 243.269,25$, sendo no município de Igrejinha beneficiadas a APAE, Esporte Clube Igrejinha e o Corpo de Bombeiros Voluntários.

E, no ano de 2016, foram auxiliadas, no município de Igrejinha, o Esporte Clube Igrejinha, Hospital Bom Pastor e o Círculo de Pais e Mestres da EMEI Raio de Sol, sendo que, o valor distribuído para as quatorze entidades dos municípios de Igrejinha, Três Coroas, Novo Hamburgo, Gramado e Canela foi de R \$ 159.679,09. Ao todo já foram distribuídos mais de $\mathrm{R}$ \$ 770.000,00 para diversas entidades localizadas na área de atuação da cooperativa, sendo que só no município de Igrejinha, objeto do estudo, foram distribuídos mais de $\mathrm{R} \$ 165.000,00$ entre as cinco entidades auxiliadas nos anos de 2012 a 2016, a saber, a APAE, o Corpo de Bombeiros Voluntários, o Hospital Bom Pastor, o Esporte Clube Igrejinha e o Círculo de Pais e Mestres da EMEI Raio de Sol.

\subsection{Análise das entrevistas com os gestores}

Como primeira indagação foi questionado sobre como surgiu o Fundo Social e Comunitário (FSC), o sujeito A explica que "O surgimento do fundo teve início desde as primeiras movimentações de fundação da cooperativa, porque desde o projeto inicial se falava em poder entregar para a comunidade algumas alternativas de melhoria, de poder alcançar para essas instituições não governamentais alguns benefícios ou algum auxílio da cooperativa através do seu resultado". Já o sujeito B afirma que "Desde o projeto de constituição da cooperativa os fundadores sempre tiveram em mente ter um percentual da sobra como um 
retorno as entidades filantrópicas e sem fins lucrativos, isso fez parte da divulgação da cooperativa desde o início e está se conseguindo cumprir este objetivo".

As respostas vão ao encontro de Savoldi et al. (2011), para quem a responsabilidade social nas cooperativas é intrínseca aos valores que as moldaram desde o início, ou seja, o envolvimento dos funcionários e cooperados com a comunidade deve partir da própria cooperativa para que haja um desenvolvimento local de forma integrada e sustentável. Contribuindo com os entrevistados,o autor Maximiano (2010), enfatiza que, as organizações, assim como as pessoas, possuem responsabilidades sociais, na proporção de que sua postura afeta os demais e, sempre haverá, pessoas ou grupos dispostos a cobrar essa responsabilidade por diversos meios, como imprensa, legislação, ativismo político e atuação dos parlamentares.

Seguindo o roteiro das entrevistas,a segundapergunta foi se a distribuição do FSC era importante para a organização e por que. De acordo com o sujeito A “É importantíssimo porque atende plenamente ao princípio cooperativista de interesse pela comunidade, o sétimo princípio". Enquanto isso, o sujeito B entende que "É importante porque era um dos objetivos fixados pelos fundadores e como cooperativa nós temos interesse, e muito, pelo desenvolvimento da comunidade. $\mathrm{O}$ fato de poder auxiliar essas instituições, que carecem de recursos, é uma forma de contribuir para o desenvolvimento do município".

Os valores e o espírito cooperativista estão materializados nos seus princípios. Portanto, o sétimo princípio retrata sobre o interesse pela comunidadee significa que as cooperativas devem trabalhar para o desenvolvimento sustentado das comunidades onde atuam através de políticas que são aprovadas por seus cooperados explica Schneider (2012).

O terceiroquestionamento se propunha em saber quais eram as principais contribuições do FSC para a melhoria do desenvolvimento social no município de Igrejinha. Na visão dos respondentes, o sujeito B afirmou que "O fato de contribuir com as entidades, possibilitando que elas possam adquirir novos equipamentos, ferramentas de trabalho ou até mesmo reformar sua estrutura física contribui para melhorar o atendimento desta entidade juntoa comunidade e assim melhorar o desenvolvimento social do município, atendendo a toda a comunidade". No mesmo sentido, o sujeito A afirmou que "No município de Igrejinha, nós contribuímos muito com a APAE, com o Esporte Clube Igrejinha, com o hospital na questão de poder melhorar o atendimento para a comunidade com a reforma de quartos e compra de equipamentos. Com bombeiros, com a questão de compra de equipamentos para a ambulância e ferramentas que os bombeiros necessitam no dia-a-dia. Então, acho que no mais é assessorar essas entidades no desenvolvimento do trabalho para a comunidade". 
Considerava-se que o aumento do crescimento econômico contribuiria ou aumentaria o desenvolvimento do país. Da deficiência deste conceito, segundo Becker (2001), surgiu o desenvolvimento sustentável, visto que o padrão de consumo das sociedades desenvolvidas é elevado, reforçando a ideia de que o desenvolvimento precisa satisfazer o bem-estar da população, ao mesmo tempo em que, não prejudica as gerações futuras, observando o meio social e ambiental.

$\mathrm{Na}$ quarta inquisição, os dois respondentes concordam entre si quantoaos critérios que são avaliados na escolha das entidades para as quais serádistribuído o FSC, o sujeito B explica que "Primeiro nós temos que avaliar se tem recurso para todo mundo, nós pedimos que os projetos sejam encaminhados antecipadamente, havendo recursos para atender todos eles, são todos atendidos", nesse sentido o sujeito A complementa que "[...] depois a orientação é que a entidade seja associada a cooperativa, a apresentação dos projetos e a avaliação se esses projetos tem um cunho sustentável, se ele vai trazer algum benefício direto para a comunidade. Nós procuramos investir em investimentos permanentes, sempre em alguma compra de equipamento, reforma, ampliação, manutenção da estrutura da entidade, compra de uniformes e coisas assim que são necessárias no dia-a-dia”.

Neste sentido,Meinen e Port (2012) salientam que as cooperativas têm o dever de encaminhar as comunidades nas quais estão inseridas para um desenvolvimento equilibrado e de bem-estar. Portanto, elas devem respeitar as característicassociais e a vocação econômica do local, desenvolvendo soluções de negócios e apoiando ações em prol da comunidade.

Como quinta e última pergunta,foi questionado se existe algum acompanhamento por parte da organização para verificar se o projeto foi realizado com sucesso,e de que forma é divulgado a distribuição do FSC. Os dois respondentes descreveram o mesmo processo de acompanhamento, segundo o sujeito B “Ainstituição tem 6 meses para apresentar um relatório de preferência até com fotos, comprovando a efetiva aplicação. E nós até, em algumas situações, fazemos questão de ir lá fazer uma visita e ver em loco se realmente isso foi efetuado". Enquanto o sujeito A complementa que "Nós divulgamos basicamente através da nossa página do facebook, na página da própria Ecocredi na internet, e agora também nós estamos fazendo um relatório social junto com a prestação de contas, com o fechamento do balanço, sendo posteriormente entregue para os associados".

O cooperativismo, de acordo com Soares e Melo Sobrinho (2008), é de singular importância para a sociedade, visto que promove a aplicação de recursos privados e assume os riscos equivalentes em favor da comunidade onde se desenvolve. Como representa iniciativas 
dos próprios cidadãos, colabora de forma eficaz para o desenvolvimento local sustentável, trazendo benefícios importantes como a geração de empregos e a distribuição de renda.

\subsection{Análise das entrevistas com as entidades}

$\mathrm{Na}$ primeira indagação ondefoi questionado sobre qual(is) projeto(s) já foi(ram) desenvolvido(s) pela entidade através do FSC distribuído pela cooperativa de crédito o sujeito A, representante da APAE, explica que "No ano de 2015nós montamos um projeto para conseguir recursos financeiros para fazer a troca do nosso carro que fazia o transporte dos alunos. Então o nosso sonho, era um carro adaptado para deficientes físicos e conseguimos com esse recurso, não só ele, mas muito dele, fazer a compra desse carro”. Já o sujeito D, representante do Hospital,afirma que "A cada ano que recebemos o FSC, fizemos vários projetos principalmente para aquisições de equipamentos, podemos citar a aquisição de quatorze camas hospitalares, uma mesa de refeição, ventilador pulmonar, monitores multíparamétricos, podemos citar também diversos equipamentos em cada projeto que fizeram com que a gente mantivesse o hospital atualizado". Enquanto que o sujeito E, representante dos Bombeiros, acrescenta que na sua entidade "[...] foram adquiridos equipamentos de segurança como roupas especiais para salvamento, equipamentos para as ambulâncias, entre outros".

Neste sentido, segundo Commodaro e Sabatiello (2011), há três campos de atuação da responsabilidade social: o ambiente de trabalho, o meio ambiente e a comunidade. $\mathrm{O}$ foco atual é o meio ambiente e a comunidade, pois vão além da empresa e representam um sentimento de responsabilidade, cumprido por espontaneidade e atitude, não somente nas obrigações da entidade ou empresa, mas com o social.

Nasegunda pergunta,foi questionado se a distribuição do FSC é importante para a entidade e por que. Todos os respondentes afirmaram que sim, além disso, o sujeito C, representante da EMEI Raio de Sol, afirma: "Nossa, muito, porque nós temos recursos que provém de eventos e promoções que a escola realiza como rifas, chás comerciais, além de um repasse que recebemos do município, mas esses valores são utilizados para a manutenção da escola, para comprar materiais escolares, pagar contas fixas, entre outros, nunca para comprar bens materiais".Neste mesmo sentido, o sujeito D,menciona que "É muito importante, porque nós utilizamos deste investimento para fazer aquisição de equipamentos, principalmente para poder aumentar a nossa estrutura tecnológica e melhorar o atendimento, através de uma 
estrutura melhor". O sujeito B, representante do Esporte Clube Igrejinha, acrescenta que "É importante, porque permite que crianças que não tem condições possam ter seu uniforme, porque nós valorizamos muito essa questão das escolinhas visto que, hoje, o esporte é um meio de educação, de formação e até de inclusão social”.

Neste contexto,Klein (2014) destaca que o interesse pela comunidade como o sétimo dos princípios cooperativistas demonstra que já em meados do século XIX, as cooperativas praticavam os conceitos que hoje em dia são difundidos sob a denominação de responsabilidade social empresarial. Ou seja, enquanto as empresas passaram a se preocupar com o fator responsabilidade social apenas em anos mais recentes - após esse fator tornar-se um diferencial competitivo no mercado - nas cooperativas, o interesse pela comunidade sempre foi uma preocupação e esteve presente desde os primórdios de sua consolidação.

Seguindo o roteiro das entrevistas,o terceiro questionamento foi se após a conclusão do projeto amparado pelo FSC, foi possível melhorar a qualidade do atendimento prestado pela entidade e de que forma.Os cinco entrevistados afirmaram que sim,o sujeito A enfatiza que "Com certeza sim. Antes nós tínhamos então um carro que não era adaptado para deficiente físico. Agora, é possível fazer o transporte de um número maior de alunos com mais qualidade". O sujeito $\mathrm{C}$ fala que "Com certeza, contemplando mais crianças, como nós só tínhamos um playground e temos um número grande de crianças, com um segundo espaço podemos atender a nossa demanda [...]". Já o sujeito E menciona que "Sem dúvida, com esses equipamentos adquiridos através do fundo, foi possível zelar pelo nosso bombeiro e com isso, ele converter um melhor atendimento para essa vítima e para a própria comunidade".

As respostas vão ao encontro de Meinen e Port (2014),os quais explicam que esse interesse pela comunidade exige das cooperativas o apoio a projetos e soluções sustentáveis no âmbito social, ambiental e também econômico (para garantir a continuidade do próprio empreendimento cooperativo). Assim, as cooperativas devem trabalhar de forma contínua, visando à melhoria da qualidade de vida de todas as pessoas dentro da sua comunidade.

A quarta inquisição buscava descobrir se o FSC contribui para a melhoria do desenvolvimento social no município de Igrejinha/RS e por que, todos os entrevistados afirmaram que sim. O sujeito B menciona que "Com certeza contribui, em face de possibilitar mais esse auxílio. Nós nos preocupamos muito, porque como estamos em uma cidade industrial onde os pais trabalham nas indústrias, as crianças fora do seu turno escolar às vezes ficam sem o que fazer e dessa forma nós tentamos, através da escolinha, suprir um pouco essa parte de atividade durante o turno inverso da escola". O sujeito A enfatiza que "Com certeza, 
a APAE é o único espaço no município de referência para atender pessoas com deficiência intelectual e múltipla.No momento que nós oferecemos um transporte de qualidade, pensando neste projeto, se consegue fazer que $100 \%$ dessas pessoas venham, então, nós temos uma adesão máxima". Nesse sentido,o sujeito C observa que "Com toda a certeza, como as crianças passam muito tempo aqui, imagina a felicidade delas de ter novamente uma coisa diferente na escola, um recurso diferente, mais o material disponível. Não só a escola, mas todas as entidades que receberam esses recursos. E esse dinheiro é investido na cidade, acho que é muito importante isso, pois em outros bancos você não sabe para onde o dinheiro vai”.

O desenvolvimento local, segundo Buarque (1999), é um processo endógeno, visto que, busca melhorar a qualidade de vida das pessoas e promover o dinamismo econômico. Para ele,o desenvolvimento local pode ser definido como um processo de mudança social que busca o aumento das oportunidades da sociedade, de maneira que seja compatível, no tempo e no espaço, com o crescimento e a eficiência econômica, a conservação ambiental, a equidade social e a qualidade de vida, mantendo uma clara preocupação com o futuro das gerações.

$\mathrm{Na}$ quinta indagação, foi perguntado quantas pessoas a entidade atende em média por mês e, se, após a finalização do projeto, esse número havia aumentado. O sujeito A respondeu que "Hoje nós atendemos então 52 alunos e mais 28 usuários que vem só para atendimentos, totalizando 80 pessoas que usam o serviço da APAE. O que se nota, não é um número crescente porque nós não trabalhamos com lista de espera, mas que esse transporte possibilitou que mais alunos viessem para a APAE, então, acaba aumentando". O sujeito B afirma que "Hoje, nós atendemos mais de 200 crianças e esse é um projeto contínuo, já trabalhamos com as escolinhas há mais de 15 anos. É difícil mensurar se o projeto aumentou a quantidade de pessoas atendidas, mas melhorou muito a qualidade do atendimento prestado".

O sujeito C explicou que "Nós neste ano estamos atendendo 123 crianças, mas acaba por beneficiar toda a família, atinge muitas pessoas, porque a partir do momento que eles estão aqui os pais podem trabalhar mais tranquilos, pois tem onde a criança ficar bem cuidada e bem alimentada. No nosso caso, melhorou a qualidade do atendimento e a diversidade do atendimento que prestamos a comunidade".O sujeito D informou que "Em 2016 foram 3.597 internações, 2.770 cirurgias, 584 partos, 51.211 atendimentos de emergência, 19.300 consultas especializadas" e ainda salientou que "O atendimento tem crescido devido a nossa estrutura tecnológica e de pessoas, também pela humanização do hospital, principalmente por ser uma referência na região. A gente tem recebido muitos pacientes de outros municípios que dessa forma tornam o hospital uma referência". E o sujeito E disse que "Em média, hoje, 
atendemos 240 ocorrências mês. No ano de 2016 foram 2287 pessoas atendidas. Nósnão temos como mensurar quantos atendimentos serão prestados no dia, gostaríamos de não atender nenhum, adquirimos o equipamento que é fundamental para a segurança do bombeiro no atendimento às vítimas, mas diante do cenário atual o número cresce cada vez mais".

Neste sentido,Srour (2003, p.316) afirma que a responsabilidade social é "[...] o compromisso das empresas com o bem-estar social", ou seja, quando estas empresas revertem seus lucros em melhorias sociais.Em consequência, as empresas abandonam velhas políticas, definem novas práticas, evoluem parcerias com as partes interessadas e isso mostra que estão preocupadas com o social Dias (2012), explica que, por sua vez, as empresas podem ser beneficiadas, ao menos no longo prazo, por sua conduta socialmente responsável, visto que, através dela é possível explorar novas oportunidades de negócios que deverão surgir a partir da preocupação com os anseios sociais, culturais e ambientais, tornando a empresa mais competitiva e se diferenciando de seus concorrentes menos responsáveis.

E, por último,como sexto questionamento, foi perguntadosobre qual o instrumento era utilizado para realizar o controle de pessoas atendidas pela entidade. Para esta pergunta o sujeito C disse que "No nosso caso é por matrículas, sempre respeitando nossa capacidade máxima da escola, normalmente há uma lista de espera, quando saí uma criança já tem outra aguardando para entrar". O sujeito E informou que "A cada atendimento, que nós fizemos, é feito um boletim de atendimento individual, para cada cidadão, então, através deste boletim é gerado a estatística mensal e anual desses dados". O sujeito A mencionou que "É através da matrícula que nós temos o número total de usuários da entidade". O sujeito B explicou que "É feita uma matrícula, devido ao convênio com a prefeitura, nós temos uma ficha de presença da criança que é preenchida e repassada para os órgãos regulamentadores". E o sujeito D, afirmou que "Dentro do hospital, nós temos software que após colocar todas as informações, nos da uma noção de quantas pessoas são atendidas e qual a sua gravidade, sendo possível consultar através de um filtro a urgência ou emergência de cada caso".

Conforme Sen (1999) a população possui um importante papel no fortalecimento das responsabilidades sociais das empresas, visto que, tem o poder de selecionar, no ato do consumo, aqueles produtos ou serviços que foram produzidos de forma responsável. Desta maneira, as pessoas são protagonistas, capazes de requerer mudanças, conforme seus valores e objetivos, sendo que a vida ocorre em cada local, cada lugar tem suas necessidades e diretrizes, tornando cada vez mais essencial a participação popular na política da sociedade. 


\section{CONSIDERAÇÕES FINAIS}

O cooperativismo é um movimento que possui uma filosofia capaz de unir crescimento econômico e bem-estar social. É através dos seus valores, princípios e ideais humanitários que o cooperativismo contribui para o desenvolvimento das comunidades.

O Rio Grande do Sul é um dos pioneiros do cooperativismo de crédito no Brasil, servindo de referência e modelo para diversos outros estados, sendo as suas cooperativas de extrema importância para o crescimento do Estado. Apesar das crises enfrentadas pela economia, as cooperativas apresentam um forte crescimento e continuam investindo no desenvolvimento social de suas comunidades.

Desta forma, o problema de pesquisa proposto foi respondido de forma plena, pois os resultados apresentam as diversas contribuições geradas pelo Fundo Social e Comunitário (FSC) para o desenvolvimento social no município de Igrejinha/RS.

O primeiro objetivo específico foi descrever a relevância do FSC para o desenvolvimento social do município de Igrejinha/RS. Conforme as entrevistas com os gestores, a criação do fundo já era idealizada desde a fundação da cooperativa, buscando auxiliar a comunidade através do resultado gerado pela cooperativa eatender ao princípio cooperativista de interesse pela comunidade. Já as entidades destacaram os principais projetos que realizaram com o FSC e enfatizaram que o fundo é muito importante porque às auxilia a melhorar a qualidade do atendimento prestado, através da compra de novos equipamentos e ferramentas de trabalho, visto que, os valores que recebem através de promoções, eventose eventuais repasses da prefeitura servem para a manutenção da sua estrutura.

O segundo objetivo foi o de identificar as contribuições do FSC para a melhoria do desenvolvimento social no município de Igrejinha/RS. De acordo com os gestores, o FSC busca assessorar as entidades no desenvolvimento do seu trabalho social junto à comunidade, seja através da compra de equipamentos, aumento da estrutura, aquisição de novos bens, entre outros.Neste mesmo sentido,as entidades destacaram que o fundo contribui para a melhoria do desenvolvimento social do município porque às auxilia no desenvolvimento de seu trabalho junto à comunidade, cada uma na sua área de atuação, além disso, também melhora a qualidade do atendimento prestado, que passa a ser mais rápido e eficiente.

O terceiro objetivo foi verificar os projetos amparados pelo FSC, que alcançaram um maior número de pessoas no município de Igrejinha/RS. Verificou-se que, de acordo com os gestores, os projetos são avaliados levando em consideração os recursos disponíveis para 
distribuição, seu cunho sustentável e os benefícios que ele irá oferecer para a comunidade, sendo posteriormente acompanhado pela cooperativa a efetiva aplicação dos recursos. Os projetos que se destacaram em número de atendimentos pelas entidades são os que foram realizados pelo Hospital Bom Pastor e Corpo de Bombeiros Voluntários, visto que, possuem uma demanda de atendimentos bastante elevada no seu dia-a-dia.

Constata-se, então, através da pesquisa documental e das entrevistas realizadas que o objetivo geral do trabalho foi plenamente alcançado. Mostrou-se as contribuições do Fundo Social e Comunitário para o desenvolvimento social do município de Igrejinha/RS.

Conclui-se que a produção deste artigo foi de grande relevância para o autor em função do conhecimento adquirido e dos resultados alcançados, em que foi possível colocar em prática os conhecimentos adquiridos, contribuindo para o meio acadêmico.Sugere-se, como forma de dar sequência à pesquisa, estudos relacionados nos outros municípios onde o FSC é distribuídoou, ainda, em outras cooperativas que disponham de um fundo de auxilio as entidades sociais da sua comunidade.

\section{REFERÊNCIAS}

ALIANÇA COOPERATIVA INTERNACIONAL. Cooperativismo: Conceitos e Princípios. ACI 2012. Disponível em: <http://www.sescooprs.coop.br/cooperativismo/conceitosprincipios> Acesso em: 05 mar.2017.

ALVES, Sérgio Darcy da Silva; SOARES, Marden Marques. Microfinanças: Democratização do crédito no Brasil Atuação do Banco Central. $3^{\mathrm{a}}$ ed. Brasília: Banco Central do Brasil,2006.

AMARO, Rogério Roque. Desenvolvimento - Um conceito ultrapassado ou em renovação?

Da teoria à prática e da prática à teoria. Cadernos de Estudos Africanos, 4, Janeiro/Julho, 2003. Disponível em: <http://http://cea.revues.org/1573> Acesso em:05/04/2017

ASHLEY, Patricia Almeida. Ética e Responsabilidade Social nos Negócios: Um conceito em construção. In: ASHLEY, Patricia Almeida (Org.). Ética e Responsabilidade Social nos Negócios. São Paulo: Saraiva, 2003. p. 2-16.

BECKER, DinizarFermiano (Org.). Desenvolvimento Sustentável: Necessidade ou possibilidade?. $3^{\text {a }}$ ed. Santa Cruz do Sul: EDUNISC, 2001. 
BUARQUE, Sérgio C. Metodologia de planejamento do desenvolvimento local e municipal sustentável: Material para orientação técnica e treinamento de multiplicadores e técnicos em planejamento local e municipal. Brasília: Projeto de Cooperação Técnica, INCRA/IICA,1999.

COMMODARO, Gianfranco; SABATIELLO, Jacopo. A empresa como Fator de Desenvolvimento do Território: Regulamentação Legislativa da Responsabilidade Social Corporativa e do Terceiro Setor. $2^{\mathrm{a}}$ Ed. Belo Horizonte, 2011.

DIAS, Reinaldo. Responsabilidade Social: fundamentos e gestão. São Paulo: Atlas, 2012.

ETGETO, Anderson Augusto et al. Os Princípios do Cooperativismo e as Cooperativas de Crédito no Brasil. In: Maringá Management: Revista Ciências Empresariais. Disponível em: <http://www.maringamanagement.com.br/novo/index.php/ojs/issue/view/2> Acesso em: 18 mar. 2017.

GAWLAK, Albino. Cooperativismo Primeiras Lições. 4ª Ed. 2010. Disponível em: <http://www.ocb.org.br/GERENCIADOR/ba/arquivos/livrocoopprimeiraslicoes2010finalfinal .pdf>. Acesso em: 10 mar. 2017.

GIL, Antônio Carlos. Métodos e Técnicas de Pesquisa Social. 6ª ed. São Paulo: Atlas, 2009.

GODOY, Dagoberto Lima. RSE: Uma visão empresarial. In: ARAUJO, Margarete Penerai (Org.). Responsabilidade social como ferramenta de política social e empresarial. Novo Hamburgo: Editora Feevale, 2004.

KLEIN, Fabrício José. Estado, empresas e desenvolvimento: princípios normativos de organização do cooperativismo. 2014. 97 p. Dissertação (Programa de Pós-Graduação em Economia) - Universidade Federal do Rio Grande do Sul, Faculdade de Ciências Econômicas, Porto Alegre, 2014.

MARTINS, Gilberto de Andrade. Estudo de Caso: Uma Estratégia de Pesquisa. $2^{\mathrm{a}}$ ed. São Paulo: Atlas, 2008. 
MAXIMIANO, Antonio Cesar Amaru. Teoria Geral da Administração: da revolução urbana à revolução digital. $6^{\mathrm{a}}$ ed. São Paulo: Atlas, 2010.

MEINEN, Ênio; PORT, Márcio. Cooperativismo financeiro: percurso histórico, perspectivas e desafios. Brasília: Confebras, 2014.

MEINEN, Ênio; PORT, Márcio. O cooperativismo de crédito ontem, hoje e amanhã. Brasília: Confebras, 2012.

MELO NETO, Francisco Paulo de; FROES, César. Gestão da Responsabilidade social corporativa: o caso brasileiro.Rio de Janeiro: Qualitymark, 2001.

ORGANIZAÇÃO DAS COOPERATIVAS BRASILEIRAS. Cooperativismo: Principios. Disponível em:<http://www.brasilcooperativo.coop.br/site/cooperativismo/principios.asp>. Acesso em: 15 mar. 2017.

PAGNUSSATT, Alcenor. Guia do Cooperativismo de Crédito: Organização, Governança e Políticas Corporativas. $1^{\text {a }}$ ed. Porto Alegre: Sagra Luzzatto, 2004.

PINHEIRO, Marcos Antonio Henriques. Cooperativas de crédito: história da evolução normativa no Brasil. $6^{\mathrm{a}}$ ed. - Brasília: BCB, 2008. Disponível em:

$<$ http://www.bcb.gov.br/htms/public/microcredito/livro_cooperativas_credito.pdf $>$. Acesso em: 20 mar. 2017.

PROGRAMA DAS NAÇÕES UNIDAS PARA O DESENVOLVIMENTO. O que é desenvolvimento humano. Conceitos. PNUD. Disponível em: $<$ http://www.br.undp.org/content/brazil/pt/home/idh0/conceitos/o-que-e-desenvolvimentohumano.html>. Acesso em: 10 abr. 2017.

RIGUEIRO, Inês Cipriano. Desenvolvimento Local Sustentável: Uma abordagem à sustentabilidade dos Projetos de Empreendedorismo Social. 2014. 127 p. Dissertação 
(Mestrado em Intervenção Social, Inovação e Empreendedorismo). Faculdade de Psicologia e Ciências da Educação e Faculdade de Economia da Universidade de Coimbra, Coimbra, 2014.

SAVOLDI, Zélia; ZAMBERLAN, Luciano; SPAREMBERGER, Ariosto. A responsabilidade social em cooperativas agropecuárias do Rio Grande do Sul. In: BÜTTENBENDER, Pedro Luís (Org.). Gestão de Cooperativas: fundamentos, estudos e práticas.Ijuí: Unijuí, 2011. P. 77-102.

SACHS, Wolfgang. Dicionário do Desenvolvimento Social: Guia para o conhecimento como poder. Petrópolis: Vozes, 2000.

SCHARDONG, Ademar. Cooperativismo de Crédito. In Expressão do Cooperativismo Gaúcho 2013. Porto Alegre: SESCOOP, 2013.

SCHNEIDER, José Odelso. A Doutrina do Cooperativismo: Análise do Alcance, do Sentido e da Atualidade dos seus Valores, Princípios e Normas nos Tempos Atuais. Disponível em:〈http://www.periodicos.adm.ufba.br/index.php/cgs/article/view/296/pdf_35> Acesso em:12 mar. 2017.

SEN, Amartya. Desenvolvimento como liberdade. 1. ed. São Paulo: Companhia das Letras, 1999.

SOARES, Marden Marques; MELO SOBRINHO, Abelardo Duarte de. Microfinanças: $O$ papel do Banco Central Do Brasil e a importância do cooperativismo de crédito. $2^{\mathrm{a}}$ ed. Brasília: Banco Central do Brasil, 2008.

SOUZA, Paulo Renato. Educação e responsabilidade social. Folha de São Paulo, São Paulo, 19 jun. 2006, Tendências/Debates, p. A3.

SROUR, Robert Henry. Ética empresarial: a gestão da reputação. Rio de Janeiro: Elsevier, 2003.

UNRISD.Social development in an uncertain world: UNRISD research agenda 20102014.Geneva, March2011. p.2. Disponível em: 〈http://www.unrisd.org/research-agenda> Acesso em: 22 mar. 2017. 